\title{
Non-motor symptoms of Parkinson's disease
}

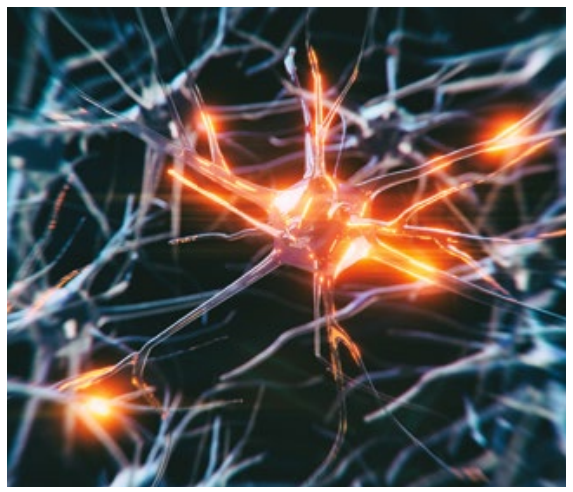

CPD

Vincent Carroll, Rachel Rossiter, Denise Blanchard

\section{Background}

Parkinson's disease is characterised by a complex array of motor and non-motor symptoms. Motor symptoms are often prioritised for assessment and treatment. Growing evidence highlights the importance of recognising the impact of non-motor symptoms on the person's quality of life.

\section{Objective}

The aim of this article is to increase awareness of the importance of identifying and addressing non-motor symptoms experienced by people living with Parkinson's disease.

\section{Discussion}

A vignette developed in collaboration with a person living with Parkinson's disease and his wife provides an 'insider perspective'. Regular assessment and monitoring of non-motor symptoms enable the clinician to support the implementation of effective interventions. Team-based care and connections with Parkinson's support groups are essential to enable the person to live well with Parkinson's disease and provide informal carers with the support and information needed.
PARKINSON'S DISEASE is a complex neurodegenerative disorder that affects people in very diverse ways and is the second most common neurological condition worldwide. ${ }^{1}$ The management of Parkinson's disease for many years has focused largely on treating and improving motor symptoms - bradykinesia combined with either rigidity, resting tremor or both. ${ }^{2}$ Non-motor symptoms - including anxiety and depression - typically pre-date the emergence of motor signs by years. ${ }^{3,4}$ Usually, a person presents with a combination of non-motor and motor symptoms ${ }^{4,5}$ that affect the person's level of disability and health-related quality of life (QoL). ${ }^{3,6,7}$ A diagnosis of Parkinson's disease should be inextricably linked to therapeutic interventions that focus on improving a patient's QoL and address both motor and non-motor symptoms. While it is essential to understand and adequately treat motor symptoms, this article draws attention to the importance of identifying and addressing non-motor symptoms experienced by the person living with Parkinson's disease. A vignette developed in collaboration with a person living with Parkinson's disease and his wife provides an 'insider perspective' (Box 1).

The aim of this article is to deepen knowledge of:

- the prevalence of non-motor symptoms in Parkinson's disease
- the impact of non-motor symptoms on the person's QoL

- validated approaches to the assessment of non-motor symptoms

- non-pharmacotherapeutic interventions for non-motor symptoms

- a team approach to care.

Early and timely referral to a neurologist or movement disorder specialist is imperative to confirm the diagnosis and establish a shared management plan for the person with Parkinson's disease. ${ }^{8}$ A confirmed diagnosis of Parkinson's disease is needed to link together non-motor symptoms that the person may have also been experiencing for years before diagnosis. A diagnosis also allows the patient and family to explore interventions to address non-motor symptoms that can be somewhat puzzling without the overarching diagnosis. The phases of Parkinson's disease are Diagnosis, Maintenance, Complex (autonomic problems prominent, five or more doses of medication, or infusion therapy) and Palliative. ${ }^{9}$ Identifying the phase of Parkinson's disease enables further tailoring of the appropriate supportive interventions.

Assessing and treating both motor and non-motor symptoms are vital to the effective management of Parkinson's disease. General practitioners (GPs) are well placed to coordinate a holistic 
approach to care for those with Parkinson's disease. The focus of GP management has been described as follows: ${ }^{8}$

- Encourage a healthy lifestyle.

- Help and guide the patient, caregiver and family to understand the disease.

- Manage the symptoms of Parkinson's disease throughout the disease.

Medication prescription for Parkinson's disease is dependent on a person's level of disability from the motor symptoms, and the impact Parkinson's disease is having on their QoL. The choice of medication should consider a person's age, lifestyle, occupation and medical history. ${ }^{8,10}$

Dopamine replacement therapy is the most effective treatment for Parkinson's disease. When motor symptoms are affecting a person's QoL, first-line treatment in the early stages of Parkinson's disease is levodopa. When motor symptoms are not affecting QoL, consideration can be given to dopamine agonists, levodopa or monoamine oxidase $\mathrm{B}$ (MAO-B) inhibitors; these can also be included as potential adjuncts later in the progression of Parkinson's disease. ${ }^{10,11}$

Motor symptoms have been described as the 'tip of the iceberg'. ${ }^{12}$ Focusing solely on motor symptoms severely disadvantages the patient, missing the opportunity to address non-motor symptoms (Box 2) affecting the person's QoL and potentially contributing to further functional decline. In 2020, Still et al described the relationship between

\section{Box 1. Vignette as told by Tony and Jenny}

For 28 years, Tony, aged 62 years, and Jenny ran a successful carpet cleaning business. Outside work Tony was active, playing A grade tennis twice weekly and swimming regularly. In 2014, Tony experienced 'terrible anxiety'; the couple attributed this to stress, deciding to sell the business. Tony developed depression. In 2016, he commenced antidepressants, trying three different types with no benefit. The company sold, and contrary to the agreement reached with the new owners, the workload did not ease. Tony's mental health continued to deteriorate.

Jenny noticed Tony's changing gait. Tony attributed his loss of smell to chemicals used for carpet cleaning; his depression deepened. He said, 'I can't live like this'. Insomnia worsening, he took to occasionally walking the streets at 1 o'clock and 2 o'clock each morning. Antidepressants appeared to make his insomnia worse. Counselling made no difference. The general practitioner referred Tony to a neurologist. Jenny suspected Parkinson's disease. The struggle with anxiety and depression delayed him seeing a neurologist until 2017.

A diagnosis of Parkinson's shocked Tony, who thought it was stress and overwork. The neurologist identified slowing gait and 'cogwheel rigidity', initially prescribing three different types of medication without any improvement to Tony's motor symptoms. Two of these were dopamine agonists: 1) a rotigotine patch was initially commenced at $2 \mathrm{mg}$, titrating slowly up to $8 \mathrm{mg}$ over six months, and caused a skin rash; 2) pramipexole was associated with somnolence and sudden onset of sleep; and 3) rasagiline, a monoamine oxidase type-B (MAO-B) inhibitor, caused excessive daytime sleepiness and nausea. Tony's mobility further decreased; he was unable to dress, clean his teeth or brush his hair without Jenny's help. His mood deteriorated further. Soon after an admission to hospital in 2018 with constipation and urinary retention, the Parkinson's nurse reassessed Tony, then consulted his neurologist, advising that Tony's struggle with immobility, depression and anxiety was affecting his quality of life. The neurologist reassessed Tony, commencing levodopa and referring Tony to a psychiatrist who was unable to help. Within three months, Tony was able to move freely, his anxiety and depression much improved.

Tony now sees a movement disorder neurologist. Tony and Jenny also contacted Dr Constantini, an Italian neurologist (died of COVID-19, May 2020) who recommended highdose thiamine hydrochloride, providing rapid relief of Tony's constipation. With ongoing support from the Parkinson's nurse, Tony is a 'lot more hopeful'. Regular Parkinson's medications and antidepressants provide pharmacological support, and Tony's mental health is 'heaps better now'. Jenny and Tony are active in Parkinson's support groups, locally and online. Tony is enrolled in three boxing and two PD Warrior sessions weekly, plays tennis and walks regularly. Tony says, 'I feel the need to exercise to maintain my physical and mental wellbeing; it helps with my quality of life. I get exhausted pushing my body, but then I can sleep well at night.'

severity of non-motor symptoms and functional disability as reported by people living with Parkinson's disease. ${ }^{13}$ The researchers highlighted the possibility that clinician measures and perceptions may not reflect the person's experience of living with Parkinson's disease and the impact of non-motor symptoms.

Table 1 presents a sample of the extensive research reporting the pervasiveness of non-motor symptoms experienced by people living with Parkinson's disease and correlation with QoL.

Emerging research is identifying different phenotypes of Parkinson's disease. Awareness of these phenotypes enables clinicians to be mindful of the non-motor and fall-related features linked to specific phenotypes, such as those associated with postural instability-gait difficulty (PIGD) and tremor-dominant subtypes. ${ }^{14}$ This area of research is in the early stages; however, findings suggest PIGD is significantly linked to fatigue, gastrointestinal dysfunction and increased fall-related risks. While it is essential to consider the phenotype of the disease, it is also important to assess all people living with Parkinson's disease for non-motor symptoms. For example, Abou Kassm et al examined anxiety as it relates to Parkinson's disease and suggest that one-third of patients with Parkinson's disease meet the criteria for an anxiety disorder. ${ }^{15}$ This may present before a diagnosis of Parkinson's disease

\section{Box 2. Non-motor symptoms of Parkinson's disease ${ }^{44}$}

- Cognitive impairment

- Cardiovascular dysfunctions

- Urinary problems

- Hallucinations and delusions

- Sexual dysfunction

- Anxiety and depression*

- Gastrointestinal symptoms (constipation*)

- Sleep disturbance (rapid eye movement sleep behaviour disorder*)

Note: Non-motor symptoms can be more troublesome and disabling than motor symptoms.

*These symptoms can occur years before a diagnosis of Parkinson's disease. 
is made. Anxiety is also a predictor of low QoL and is often overlooked or confused with depression.

The Non-Motor Symptoms Scale (NMSS) is a comprehensive assessment capturing many of the non-motor symptoms associated with Parkinson's disease. More than 100 clinical trials and studies have shown strong correlations between NMSS burden and health-related QoL measures. The NMSS covers 30 non-motor symptoms grouped into nine domains, providing a roadmap to assist quantifying the far-reaching burden of non-motor symptoms in people with Parkinson's disease. ${ }^{1-3}$ The shortened version of the scale can be accessed online from Parkinson's UK (www.parkinsons. org.uk/sites/default/files/2021-04/ Fillable\%20NMS\%20questionnaire. pdf). Using a screening tool regularly helps identify non-motor symptoms, which then allows clinicians to tailor an individualised plan to address the specific needs of the person. ${ }^{2,4}$ A 2019 medicine review provides a comprehensive update of evidence-based pharmacological recommendations for an extensive range of non-motor symptoms experienced by people with Parkinson's disease. ${ }^{16}$ Referral to this resource is recommended; it can be accessed online (https:// movementdisorders.onlinelibrary.wiley. com/doi/epdf/10.1002/mds.27602).

Recent findings suggest that non-pharmacological interventions to address non-motor symptoms may be underrecognised and underemphasised by both doctors and patients. ${ }^{7,17,18}$

However, a growing body of research shows the benefits of a range of different interventions. Exercise in many forms has emerged as a prominent adjunct therapy, helping alleviate symptoms associated with Parkinson's disease. These include the motor and non-motor symptoms; reducing falls risk; improving gait and strength, cognition and sleep quality; reducing stress and anxiety; and improving disease progression and QoL. ${ }^{19}$ The exercise types include aerobic exercise, dancing, aquatic, yoga and boxing, ${ }^{19-32}$ and Kalyani et $\mathrm{al}^{33}$ propose benefits may arise because of the release of dopamine and sometimes the ongoing engagement with other people.
Speech problems affect up to 51-90\% of people with Parkinson's disease. Dysarthria is common, characterised by reduced loudness, limited respiratory support, monotone voice and reduced voice quality. Speech pathology intervention programs and singing and voice therapy have the potential to improve voice-related QoL and respiratory function, as well as increase voice loudness and communication. ${ }^{22,34,35}$

Another important issue requiring careful attention relates to the need for caregiver and social support. Insufficient psychosocial support may be associated with poorer psychosocial outcomes for people with Parkinson's disease. ${ }^{36}$ However, intimate relationships with loved ones with Parkinson's disease are increasingly characterised by reduced mutuality. The individual becomes an informal carer rather than a partner and experiences high levels of burden and strain. ${ }^{37-40}$ Given the progressive nature of Parkinson's disease and the increasing burden, especially as the patient moves from the maintenance to complex phase, regular assessment of the caregiver's needs in conjunction with referral to additional support services is imperative.

Early referral to a specialist Parkinson's nurse whose expanded role of advanced practice can support self-management and an enhanced QoL from diagnosis and through the complexities that arise as the disease progresses is recommended. The specialist nurse can likewise support the person and their family when transition to palliative care is needed. Engagement with a Parkinson's support group can offer additional information and resources and help to reduce social isolation through friendship and shared experiences. GPs can encourage both the person with Parkinson's disease and family members to contact the peak body for Parkinson's in the state as a further source of information, and for links to relevant support services.

The complexity of Parkinson's disease requires individualised care. Figure 1 presents the key components of effective team-based care. ${ }^{41-43}$

Table 1. Prevalence of non-motor symptoms and correlation with QoL

\begin{tabular}{|c|c|c|}
\hline Study & Sample size & Findings \\
\hline \multirow[t]{2}{*}{$\begin{array}{l}\text { Chaudhuri et al } \\
(2021)^{44}\end{array}$} & $n=75$ & $\begin{array}{l}100 \% \text { of patients with Parkinson's disease identified } \\
\text { at least one non-motor symptom }\end{array}$ \\
\hline & & $\begin{array}{l}\text { Higher prevalence of non-motor symptoms in those } \\
\text { with disease duration }>9 \text { years }\end{array}$ \\
\hline \multirow[t]{7}{*}{$\begin{array}{l}\text { Gulunay et al } \\
(2020)^{12}\end{array}$} & $n=75$ & $\begin{array}{l}100 \% \text { of patients with Parkinson's disease identified } \\
\text { at least one non-motor symptom: }\end{array}$ \\
\hline & & - fatigue $(58 \%)$ \\
\hline & & - anxiety (56\%) \\
\hline & & - leg pain (38\%) \\
\hline & & • insomnia (37\%) \\
\hline & & - urgency/nocturia (35\%) \\
\hline & & - drooling (31\%) \\
\hline \multirow[t]{3}{*}{$\begin{array}{l}\text { Müller et al } \\
(2013)^{17}\end{array}$} & $n=166$ & $\begin{array}{l}\text { Non-motor symptoms remain a concern three years } \\
\text { after diagnosis }\end{array}$ \\
\hline & & $\begin{array}{l}\text { Affect quality of life (QoL) as measured by the 36-Item } \\
\text { Short Form Health Survey }\end{array}$ \\
\hline & & $\begin{array}{l}\text { Non-motor symptoms should be treated as they } \\
\text { contribute primarily to reduced QoL }\end{array}$ \\
\hline $\begin{array}{l}\text { Nicoletti et al } \\
(2017)^{7}\end{array}$ & $n=272$ & $\begin{array}{l}\text { Decreased QoL score correlated with Parkinson's } \\
\text { Fatigue Scale, Beck Depression Inventory, Unified } \\
\text { Parkinson's Disease Rating Scale Section I, Parkinson's } \\
\text { Disease Sleep Scale }\end{array}$ \\
\hline
\end{tabular}




\section{Conclusion}

The complexity and progressive neurodegeneration that characterise Parkinson's disease have a severe impact on the QoL of the person living with the disease. Family members and informal carers experience increasing levels of caregiver burden as the person's physical, cognitive and psychological health deteriorates. Careful attention across each phase of Parkinson's disease, with regular assessment of non-motor symptoms and a team-based approach to individualised care, is key to maximising the person's QoL and reducing emergency presentations to hospital. It is important to ensure that the team includes a specialist Parkinson's nurse and allied health professionals. Wherever possible, the GP should ensure referral to a movement disorder neurologist or geriatrician and request regular review of medication regimens. It is critical to listen carefully to the person's experience and engage regularly with the person's informal caregiver and family to ensure adequate supports are in place. Linking the person and their carer to the Parkinson's peak body within their state or region and the local support group will help to reduce social isolation and enable access to additional consumer-focused information.

\section{Key points}

- The non-motor symptoms of Parkinson's disease are more disabling than the motor symptoms.

- Dopamine replacement therapy remains the most effective pharmacological intervention in Parkinson's disease.

- Focused exercise programs have been shown to alleviate Parkinson's symptoms.
- GPs can enable a connection with specialist Parkinson's nurses and Parkinson's support groups.

- It is important to ensure adequate support services are in place for informal carers and family.

\section{Authors}

Vincent Carroll RN, GradDip Business Administration, BHealthSci (Nursing), MSci (Dementia Care), Parkinson's Clinical Nurse Consultant, Mid North Coast Local Health District, NSW Health, Port Macquarie, NSW: School of Nursing, Paramedicine and Healthcare Sciences, Faculty of Science and Health, Charles Sturt University, Orange, NSW; Parkinson's NSW

Rachel Rossiter RN, MNursing (Nurse Practitioner), Doctor of Health Science, Associate Professor of

Nursing, School of Nursing, Paramedicine and Healthcare Sciences, Faculty of Science and Health, Charles Sturt University, Orange, NSW; Parkinson's NSW

Denise Blanchard RN, PhD, Associate Professor, School of Nursing and Midwifery, College of Health, Medicine and Wellbeing, University of Newcastle Central Coast Clinical School, Gosford, NSW

Effective care for the person with Parkinson's disease

\section{Person-centred}

\begin{tabular}{|c|c|c|c|}
\hline \multirow{2}{*}{$\begin{array}{l}\text { Across the entire } \\
\text { continuum of care } \\
\text { including diagnosis, } \\
\text { supportive treatment, } \\
\text { management } \\
\text { of increasing } \\
\text { complexity to } \\
\text { palliative care }\end{array}$} & \multicolumn{3}{|c|}{$\begin{array}{l}\text { Comprehensive care delivered collaboratively } \\
\text { Connect with specialist Parkinson's nurse } \\
\text { Focus: Living well with Parkinson's disease }\end{array}$} \\
\hline & $\begin{array}{l}\text { Address motor } \\
\text { and non-motor } \\
\text { symptoms }\end{array}$ & $\begin{array}{l}\text { Early interventi } \\
\text { community reh }\end{array}$ & $\begin{array}{l}\text { cialist treatment, } \\
\text { ion and support }\end{array}$ \\
\hline $\begin{array}{l}\text { Access to and } \\
\text { engagement with } \\
\text { a multidisciplinary } \\
\text { team including } \\
\text { physiotherapy, } \\
\text { speech pathology, } \\
\text { occupational therapy }\end{array}$ & $\begin{array}{c}\text { Facilitate } \\
\text { engagement } \\
\text { with community } \\
\text { Parkinson's } \\
\text { support groups }\end{array}$ & $\begin{array}{l}\text { Equity of } \\
\text { access } \\
\text { across urban, } \\
\text { regional, rural } \\
\text { and remote } \\
\text { locations } \\
\text { Use telehealth }\end{array}$ & $\begin{array}{l}\text { Support family } \\
\text { and carers }\end{array}$ \\
\hline
\end{tabular}

Figure 1. Effective team-based care for a person living with Parkinson's disease ${ }^{39,40}$ 
Competing interests: None.

Funding: None.

Provenance and peer review: Commissioned, externally peer reviewed.

\section{Correspondence to:}

vcarroll@csu.edu.au

\section{Acknowledgements}

The authors would like to thank Tony and Jenny Bienefelt for sharing their lived experience of Parkinson's disease.

\section{References}

1. Lovegrove CJ, Bannigan K. What is the lived experience of anxiety for people with Parkinson's? A phenomenological study. PLoS One 2021;16(4):e0249390. doi: 10.1371/journal. pone.0249390.

2. Postuma RB, Berg D, Stern M, et al. MDS clinical diagnostic criteria for Parkinson's disease. Mov Disord 2015;30(12):1591-601. doi: 10.1002/ mds.26424.

3. Broen MP, Köhler S, Moonen AJ, et al. Modeling anxiety in Parkinson's disease. Mov Disord 2016;31(3):310-16. doi: 10.1002/mds.26461.

4. Hayes MW, Fung VS, Kimber TE, O'Sullivan JD. Updates and advances in the treatment of Parkinson disease. Med J Aust 2019;211(6):277-83. doi: 10.5694/mja2.50224.

5. Carroll V, Maunsell K, Andrews J. Clinical guidelines for the care and management of patients with Parkinson's disease at presentation and admission to hospital. Coffs Harbour, NSW: Mid North Coast Local Health District, 2017.

6. Raeder V, Boura I, Leta $\bigvee$, et al. Rotigotine transdermal patch for motor and non-motor Parkinson's disease: A review of 12 years' clinical experience. CNS Drugs 2021;35(2):215-31. doi: 10.1007/s40263-020-00788-4.

7. Nicoletti A, Mostile G, Stocchi F, et al. Factors influencing psychological well-being in patients with Parkinson's disease. PLoS One 2017;12(12):e0189682. doi: 10.1371/journal. pone.0189682.

8. Rodrigues J. Parkinson's disease. A general practice approach. 3rd edn. Nedlands, WA: Parkinson's Western Australia, 2017.

9. Parkinson's UK. 2019 UK Parkinson's audit. Patient management: Elderly care \& neurology. Standards and guidance. London, UK: Parkinson's UK, 2019.

10. National Institute for Health and Care Excellence. Parkinson's disease in adults [NG71]. London, UK: NICE, 2017

11. de Bie RMA, Clarke CE, Espay AJ, Fox SH, Lang AE. Initiation of pharmacological therapy in Parkinson's disease: When, why, and how. Lancet Neurol 2020;19(5):452-61. doi: 10.1016/S14744422(20)30036-3.

12. Gulunay A, Cakmakli GY, Yon MI, Ulusoy EK, Karakoc M. Frequency of non-motor symptoms and their impact on the quality of life in patients with Parkinson's disease: A prospective descriptive case series. Psychogeriatrics 2020;20(2):206-11. doi: 10.1111/psyg.12489.

13. Still A, Hale L, Swain N, Jayakaran P. Selfreported depression and anxiety are correlated with functional disability in Parkinson's disease. NZ J Physioth 2021;49(1):40-49. doi: 10.15619/ NZJP/49.1.06.

14. Kwon KY, Lee EJ, Lee M, Ju H, Im K. Impact of motor subtype on non-motor symptoms and fallrelated features in patients with early Parkinson's disease. Geriatr Gerontol Int 2021;21(5):416-20. doi: 10.1111/ggi.14156.
15. Abou Kassm S, Naja W, Haddad R, Pelissolo A. The relationship between anxiety disorders and parkinson's disease: Clinical and therapeutic issues. Curr Psychiatry Rep 2021;23(4):20. doi: 10.1007/s11920-021-01229-9.

16. Seppi K, Ray Chaudhuri K, Coelho M, et al. Update on treatments for nonmotor symptoms of Parkinson's disease - An evidence-based medicine review. Mov Disord 2019;34(2):180-98. doi: 10.1002/mds.27602.

17. Müller B, Assmus J, Herlofson K, Larsen JP, Tysnes OB. Importance of motor vs. non-motor symptoms for health-related quality of life in early Parkinson's disease. Parkinsonism Relat Disord 2013;19(11):1027-32. doi: 10.1016/j. parkreldis.2013.07.010.

18. Fil A, Cano-de-la-Cuerda R, Muñoz-Hellín E Vela L, Ramiro-González M, Fernández-de-LasPeñas C. Pain in Parkinson disease: A review of the literature. Parkinsonism Relat Disord 2013;19(3):285-94; discussion 285. doi: 10.1016/j. parkreldis.2012.11.009.

19. Emig M, George T, Zhang JK, Soudagar-Turkey M. The role of exercise in Parkinson's disease. J Geriatr Psychiatry Neurol 2021;34(4):321-30. doi: 10.1177/08919887211018273.

20. Combs SA, Diehl MD, Chrzastowski C, et al. Community-based group exercise for persons with Parkinson disease: A randomized controlled trial. NeuroRehabilitation 2013;32(1):117-24. doi: 10.3233/NRE-130828.

21. Volpe D, Signorini M, Marchetto A, Lynch T, Morris ME. A comparison of Irish set dancing and exercises for people with Parkinson's disease: A phase II feasibility study. BMC Geriatr 2013;13:54. doi: 10.1186/1471-2318-13-54.

22. Schaible F, Maier F, Buchwitz TM, et al. Effects of Lee Silverman Voice Treatment BIG and conventional physiotherapy on nonmotor and motor symptoms in Parkinson's disease: A randomized controlled study comparing three exercise models. Ther Adv Neurol Disord 2021;14:1756286420986744. doi: 10.1177/1756286420986744.

23. Fiorelli CM, Ciolac EG, Simieli L, et al. Differential acute effect of high-intensity interval or continuous moderate exercise on cognition in individuals with Parkinson's disease. J Phys Act Health 2019;16(2):157-64. doi: 10.1123/ jpah.2018-0189.

24. Harvey M, Weston KL, Gray WK, et al. High-intensity interval training in people with Parkinson's disease: A randomized, controlled feasibility trial. Clin Rehabil 2019;33(3):428-38. doi: 10.1177/0269215518815221.

25. Horne JT, Soh D, Cordato DJ, Campbell ML, Schwartz RS. Functional outcomes of an integrated Parkinson's Disease Wellbeing Program. Australas J Ageing 2020;39(1):e94-102. doi: 10.1111/ajag.12705.

26. Miller Koop M, Rosenfeldt AB, Alberts JL. Mobility improves after high intensity aerobic exercise in individuals with Parkinson's disease. J Neurol Sci 2019;399:187-93. doi: 10.1016/j.jns.2019.02.031.

27. Pereira APS, Marinho V, Gupta D, Magalhães F, Ayres C, Teixeira S. Music therapy and dance as gait rehabilitation in patients with Parkinson disease: A review of evidence. J Geriatr Psychiatry Neurol 2019;32(1):49-56. doi: 10.1177/0891988718819858.

28. Pradhan S. The use of commercially available games for a combined physical and cognitive challenge during exercise for individuals with Parkinson's disease - A case series report.
Physiother Theory Pract 2019;35(4):355-62. doi: 10.1080/09593985.2018.1444118.

29. Raje P, Ning S, Branson C, Saint-Hilaire M, de Leon MP, DePold Hohler A. Self-reported exercise trends in Parkinson's disease patients. Complement Ther Med 2019;42:37-41. doi: 10.1016/j.ctim.2018.09.016.

30. Solla P, Cugusi L, Bertoli M, et al. Sardinian folk dance for individuals with Parkinson's disease: A randomized controlled pilot trial. J Altern Complement Med 2019;25(3):305-16. doi: 10.1089/acm.2018.0413.

31. Stuckenschneider T, Askew CD, Menêses AL, Baake R, Weber J, Schneider S. The effect of different exercise modes on domain-specific cognitive function in patients suffering from Parkinson's disease: A systematic review of randomized controlled trials. J Parkinsons Dis 2019;9(1):73-95. doi: 10.3233/JPD-181484.

32. Tollár J, Nagy F, Kovács N, Hortobágyi T. Twoyear agility maintenance training slows the progression of Parkinsonian symptoms. Med Sci Sports Exerc 2019;51(2):237-45. doi: 10.1249/ MSS.0000000000001793.

33. Kalyani HHN, Sullivan KA, Moyle G, Brauer S, Jeffrey ER, Kerr GK. Impacts of dance on cognition, psychological symptoms and quality of life in Parkinson's disease. NeuroRehabilitation 2019;45(2):273-83. doi: 10.3233/NRE-192788.

34. Tamplin J, Morris ME, Marigliani C, Baker FA, Vogel AP. ParkinSong: A controlled trial of singing-based therapy for Parkinson's disease. Neurorehabil Neural Repair 2019;33(6):453-63. doi: 10.1177/1545968319847948.

35. Sackley CM, Smith CH, Rick CE, et al. Lee Silverman Voice Treatment versus standard speech and language therapy versus control in Parkinson's disease: A pilot randomised controlled trial (PD COMM pilot). Pilot Feasibility Stud 2018;4:30. doi: 10.1186/s40814-017-0222-z.

36. Perrin PB, Henry RS, Donovan EK, et al. Parkinson's family needs and caregiver mental health: A cross-cultural comparison between Mexico and the United States. NeuroRehabilitation 2019;45(4):433-42. doi: 10.3233/NRE-192894.

37. Karlstedt M, Fereshtehnejad SM, Aarsland D, Lökk J. Mediating effect of mutuality on caregiver burden in Parkinson's disease partners. Aging Ment Health 2020;24(9):1421-28. doi: 10.1080/13607863.2019.1619165.

38. Abendroth M. Psychometric testing and modification of the Parkinson's disease caregiver strain risk screen. J Nurs Meas 2016;24(2):281-95. doi: 10.1891/1061-3749.24.2.281.

39. Abendroth M. Development and initial validation of a Parkinson's disease caregiver strain risk screen. J Nurs Meas 2015;23(1):4-21. doi: 10.1891/10613749.23.1.4.

40. Hand A, Oates LL, Gray WK, Walker RW. The role and profile of the informal carer in meeting the needs of people with advancing Parkinson's disease. Aging Ment Health 2019;23(3):337-44 doi: 10.1080/13607863.2017.1421612.

41. Rossiter R, Bramble M, Matheson A, Carroll V, Phillips R. Evaluating the impact of two specialist Parkinson's disease nurse positions in regional New South Wales, Australia: A qualitative descriptive study. Orange, NSW: Charles Sturt University, 2019.

42. Eggers C, Dano R, Schill J, et al. Patient-centered integrated healthcare improves quality of life in Parkinson's disease patients: A randomized controlled trial. J Neurol 2018;265(4):764-73. doi: 10.1007/s00415-018-8761-7. 
43. Tenison E, Smink A, Redwood S, et al. Proactive and integrated management and empowerment in Parkinson's disease: Designing a new model of care. Parkinsons Dis 2020;2020:8673087. doi: 10.1155/2020/8673087.

44. Chaudhuri JR, Mridula KR, Bandaru VCSS, Prevalence of non-motor symptoms in Parkinson's disease: A study from South India. Turk J Neurol 2021;27(1):52-57. doi: 10.4274/tnd.2021.52993. 